\title{
AS RODAS DE CONVERSA COMO FERRAMENTA COMPLEMENTAR AO PRÉ-NATAL
}

SILVA, I.S. ${ }^{1}$, XAVIER, P.B. ${ }^{2}$, ARAUJO, T.L.L ${ }^{3}$, PAULINO, D.A. ${ }^{4}$, QUEIROZ, C.G. ${ }^{5}$, BRANDÃO, G.C.G. $^{6}$

${ }^{1}$ Graduanda em Enfermagem pela Universidade Federal de Campina Grande (UFCG). E-mail: isis1998.siqueira.silva@gmail.com; ${ }^{2}$ Graduando em Enfermagem pela Universidade Federal de Campina Grande (UFCG). E-mail: pedrobx37@ gtmail.com; ${ }^{3}$ Graduanda em Enfermagem pela Universidade Federal de Campina Grande (UFCG). E-mail:thaislaraujo2@gmail.com. ${ }^{4}$ Psicólogo.Graduando em Medicina pela Universidade Federal de Campina Grande (UFCG). E-mail:danielpaulinoufcg@gmail.com; ${ }^{5}$ Graduanda em Psicologia pela

Universidade Federal de Campina Grande (UFCG). E-mail:milapsicologia2017@gmail.com; 'Enfermeira, Doutora em Ciências, Docente Adjunta III do curso de Enfermagem da Universidade Federal de Campina Grande, Coordenadora do Projeto de Extensão. Email:gisettibrandao@gmail.com

Artigo submetido em outubro de 2019 - DOI 10.32356/exta.v19.n1.42280

\section{RESUMO}

Trata-se um relato de experiência no qual utilizouse das Rodas de Conversa e metodologias ativas e participativas em encontros com gestantes em uma UBSF de Campina Grande, realizado no período de maio a dezembro de 2018. Tal experiência foi fruto de um projeto de extensão envolvendo os cursos de enfermagem, medicina e psicologia da UFCG. Este estudo buscou ressaltar a importância das rodas de conversa na promoção e prevenção em saúde de gestantes e puérperas, bem como foi possível entrelaçar o saber científico com o saber popular, permitindo uma troca de conhecimentos acerca das temáticas abordadas com as gestantes. Os membros do Projeto de Extensão saíram do papel de detentores do saber, o que favoreceu a discussão e fortaleceu o vínculo entre usuários e UBS, permitindo a construção de um conhecimento que vincula teoria e prática. Portanto, as experiências vivenciadas nas rodas de conversas foram fundamentais para o aprendizado, pois consolidaram as práticas de educação e promoção em saúde.

PALAVRAS-CHAVE: Rodas de Conversa. Pré-natal. Saúde coletiva. Educação em Saúde.

\section{CONVERSATION CIRCLES AS A COMPLEMENTARY TOOL TO PRENATAL CARE}

\begin{abstract}
This is an experience report with Conversation Circles and active and participatory methodologies used with pregnant women meetings at a health center in Campina Grande; carried out from May to December 2018. This experience was the result of an extension project involving nursing, medicine and psychology courses of UFCG. This work aims to highlight the importance of circles of conversation in promoting and prevention of pregnant and puerperal women's health, as well as it was possible to entangle scientific and popular knowledge allowing the exchange of
\end{abstract}

knowledge about the themes approached with the pregnant participants. The members of the extension project left the role of the holder of knowledge, favoring discussions and strengthening the bond between Health Service and users, also building a connection between theory and practice. Thus, the experiences lived in the Conversation Circles were essential for learning as they consolidated practices in health promotion and education.

KEYWORDS: Circles of Conversation. Prenatal. Collective Health. Health Education.

\section{INTRODUÇÃO}

A Atenção Básica (AB) caracteriza-se como a principal porta de entrada ao Sistema Único de Saúde (SUS), cumprindo papel estratégico na rede de atenção, servindo como base para seu ordenamento e efetivação da integralidade em saúde. A Estratégia de Saúde da Família e Comunidade é protagonista na ação junto à população, constituída por uma equipe 
multiprofissional e dirigida aos moradores de um território definido, sobre as quais as equipes assumem responsabilidade sanitária. A realização de ações de educação em saúde à população é uma importante ferramenta de aproximação entre profissionais e usuários da AB (BRASIL, 2017).

A educação em saúde pode ser vista como um momento de ressignificação da Estratégia de Saúde da Família, visto que, tem caráter emancipatório, e apresenta ações voltadas para o indivíduo e não para a doença à medida que os saberes são trocados, e se constrói, de maneira coletiva, um novo saber. A valorização do indivíduo por parte dos profissionais induz a sua participação no cuidado com a saúde, e assim pode passar a valorizar as estratégias de prevenção à saúde.

Nesse contexto, as práticas de Educação em Saúde devem respeitar e valorizar a participação e a autonomia dos sujeitos e possibilitar que sejam supridas suas necessidades, carências, expectativas, anseios e dúvidas. No entanto, o que se observa é a educação bancária, aplicada em especial, com as massas populares, muitas vezes realizada apenas como ato de transferência e depósito de conteúdo, desconectados da realidade vivenciada pelo sujeito e do contexto no qual se encontra inserido (FREIRE, 1967).

Nesse sentido, se faz necessário implementar ações que valorizem o saber popular e as necessidades dos usuários a partir das demandas problematizadas pelo coletivo. Para tanto, a prática da problematização deve promover entre os participantes o diálogo, a autonomia e estimular os usuários a adotarem uma postura ativa no seu ambiente, sendo fundamental na construção de um processo educativo (FERNANDES E BACKES, 2010).

Este trabalho tem como objetivo ressaltar a importância das Rodas de Conversa (RC) na promoção e prevenção em saúde de gestantes e puérperas da Unidade Básica de Saúde da Família Adalberto César (UBSF- Adalberto César), em Campina Grande-PB.

\section{A EDUCAÇÃO EM SAÚDE}

A metodologia da problematização tensiona o modelo tecnocientífico, com seus processos de análise da realidade e de construção do conhecimento. Pode mesmo vir a reorientar o entendimento sobre adoecimento, pois garante maior visibilidade às questões sociais, culturais e psicológicas do indivíduo/paciente. Ademais facilita a ruptura de paradigmas em educação, possibilitando formar profissionais em Saúde com novos pensamentos (DARIUS, 2017). 
Dessa forma, pela perspectiva problematizadora, as ações educativas em grupos na atenção básica devem estar de acordo com a realidade dos usuários, suas experiências, vivências e necessidades a partir das quais se constroem as temáticas de trabalho.

Os grupos são considerados ferramentas importantes para a promoção da saúde e para educação em saúde. Além disso, também são espaço de escuta, em que o coordenador pontua e problematiza as falas para dar oportunidade para os participantes pensarem, falarem de si e poderem elaborar melhor suas próprias questões. Essas ações ampliam as possibilidades de controle das doenças, de reabilitação e de tomada de decisões que favoreçam uma vida saudável (BASTOS, 2010).

Na prática de educação e saúde, existem as Rodas de Conversa (RC), baseada nas teorias de Paulo Freire, consistem em um espaço no qual as pessoas se dispõem circularmente, possibilitando que o mútuo olhar e comunicar dos participantes, realizando assim uma dialética pautada nos conhecimentos e experiências pessoais de cada um.

As RC's como instrumento metodológico abrem espaço para que os sujeitos envolvidos no processo de ensino e aprendizagem estabeleçam um espaço de diálogos e interações no contexto da temática, ampliando suas percepções sobre si e sobre o outro, em um movimento de alteridade e compreensão sobre a voz do outro em seu contínuo espaço de tempo (BARBOSA E HORN, 2008).

No contexto de saúde, a temática a ser discutida pode ser direcionada em prol do que a equipe profissional deseja trabalhar naquele momento, buscando temas que sejam de real interesse dos usuários, propiciando a motivação em sua participação, e desta forma, cumprindo os objetivos educativos para a saúde (SAMPAIO, 2014).

\section{MATERIAIS E MÉTODOS}

Este trabalho é um relato de experiência com caráter de descritivo e abordagem qualitativa. Segundo Lopes (2012), um relato de experiência pertence ao domínio social, fazendo parte das experiências humanas, devendo conter tanto impressões observadas quanto conjecturadas.

Foi um trabalho realizado no período de maio à dezembro de 2018 como parte do projeto de extensão Ações em Educação em Saúde com a gestante na perspectiva do Ensinar e Aprender, envolvendo os três cursos de saúde (enfermagem, medicina e psicologia) do Centro de Ciências Biológicas e da Saúde (CCBS), da Universidade Federal de Campina Grande (UFCG). 
O projeto foi desenvolvido na Unidade Básica de Saúde da Família Adalberto César, em Campina Grande - PB. Localizada na zona urbana da cidade, em bairro conhecido como local de vulnerabilidade e elevados índices de violência. A unidade foi escolhida por ser campo de atuação da UFCG. Infelizmente os dados coletados na própria unidade em termos de abrangência do serviço, mapeamento e número de famílias cobertas estavam insuficientes ou inexistentes no momento do trabalho.

Para realização deste trabalho foram utilizadas Rodas de Conversa com grupos de gestantes atendidas na referida unidade, para tanto foram utilizadas metodologias ativas e participativas que estimulavam e valorizavam o contato e o saber dos atores envolvidos. O número de gestantes variava de acordo com cada encontro, dependendo do fluxo de atendimentos do dia. Quanto à equipe de discentes era composta sempre de três participantes contando com cada um dos cursos citados acima, a professora orientadora esteve presente no primeiro encontro. Vale ressaltar que o formato de rodas de conversa, através da dialética, permite ao pesquisador se inserir como sujeito da pesquisa pela participação na conversa

O uso das metodologias ativas de ensino e aprendizagem promove a socialização dos atores envolvidos na aprendizagem, o compartilhamento de conhecimentos, a reflexão sobre os conteúdos teóricos e práticos, e acima de tudo, torna o processo educativo mais dinâmico e participativo (CARRARO et. al, 2011).

Abaixo estão dispostas as descrições de nossas atividades, as quais ocorreram em três etapas:

\section{QUADRO 1 - ETAPAS DAS ATIVIDADES REALIZADAS}

\begin{tabular}{|c|c|}
\hline ETAPAS & ATIVIDADES REALIZADAS \\
\hline $\begin{array}{l}\text { Primeiro Momento: } \\
\text { Planejamento das atividades e } \\
\text { discussão com a equipe acadêmica e } \\
\text { da unidade acerca do projeto. }\end{array}$ & $\begin{array}{l}\text { - Reunião com a equipe da Unidade de Saúde } \\
\text { para apresentação do projeto; } \\
\text { - } \quad \text { Rodas de conversas com a equipe } \\
\text { acadêmica para construir a forma de trabalhar } \\
\text { com as metodologias ativas e participativas; } \\
\text { - Construção do cronograma de rodas de } \\
\text { conversa e oficinas com as gestantes, a fim de não } \\
\text { interferir na dinâmica de atendimento da Unidade } \\
\text { Básica de Saúde. }\end{array}$ \\
\hline $\begin{array}{l}\text { Segundo Momento: } \\
\text { Levantamento dos temas mais } \\
\text { importantes, planejamento e realização } \\
\text { das RC's, no período de junho à } \\
\text { setembro/2018 }\end{array}$ & $\begin{array}{l}\text { - } \quad \text { Levantamento das necessidades das } \\
\text { gestantes e temas a serem abordados, sendo os } \\
\text { temas definidos em grupo; } \\
\text { - } \quad \text { Baseadas nas decisões anteriores, as RC } \\
\text { foram iniciadas; } \\
\text { - Discussão de equipe acadêmica acerca das }\end{array}$ \\
\hline
\end{tabular}


RC executadas.

Terceiro Momento:

Discussão dos resultados das RC's. Ocorreu entre setembro e dezembro/2018
- $\quad$ Realização de reuniões de trabalho para consolidação dos pontos levantados acerca dos temas trabalhados nas oficinas;

- Divisão de Grupos de estudo para aprofundamento das temáticas que foram abordadas nas oficinas;

- Reunião com a equipe da UBSF para compartilhar os saberes construídos nas oficinas.

- $\quad$ Elaboração de trabalhos científicos e artigo

FONTE: COLETA DE DADOS PROBEX

Tais momentos aconteceram de forma simultânea. As reuniões e discussões de planejamento ocorreram periodicamente com o objetivo de discutir e planejar os passos seguintes nas Rodas de Conversa, permitindo também o compartilhamento dos saberes e experiências vivenciadas durante os encontros com as gestantes.

\section{RESULTADOS E DISCUSSÕES}

Os temas abordados nas Rodas de Conversa foram decididos a partir das demandas das próprias gestantes e no diálogo com as mesmas. Obtendo-se portanto, as seguintes temáticas: Sexualidade na gestação, Momento do Parto, Primeiros Cuidados com o Recém-nascido e Amamentação. No quadro 2 se encontra a organização de cada RC. Cada temática foi trabalhada pelo período de um mês, ocorrendo o total de 15 encontros.

\section{QUADRO 2 - CARACTERIZAÇÃO DAS RODAS DE CONVERSA}

\begin{tabular}{l|l|l|l|l}
\hline PERÍODO & $\begin{array}{l}\mathbf{N}^{\circ} \\
\text { DE } \\
\text { RC }\end{array}$ & TEMÁTICA & \multicolumn{1}{|c|}{$\begin{array}{c}\text { PERGUNTA } \\
\text { NORTEADORA }\end{array}$} & \multicolumn{1}{|c}{ OBJETIVO } \\
\hline $\begin{array}{l}\text { Junho/ } \\
2018\end{array}$ & 05 & $\begin{array}{l}\text { Sexualidade na } \\
\text { gestação. }\end{array}$ & $\begin{array}{l}\text { Como a gestante } \\
\text { vivencia a } \\
\text { sexualidade na fase } \\
\text { gestacional? }\end{array}$ & $\begin{array}{l}\text { Apresentar a temática da } \\
\text { Sexualidade para as } \\
\text { gestantes em uma roda de } \\
\text { conversa. }\end{array}$ \\
\hline $\begin{array}{l}\text { Julho/ } \\
2018\end{array}$ & 04 & $\begin{array}{l}\text { Expectativas } \\
\text { para o momento } \\
\text { do parto }\end{array}$ & $\begin{array}{l}\text { O que as gestantes } \\
\text { esperam no } \\
\text { momento do parto? }\end{array}$ & $\begin{array}{l}\text { Compartilhar saberes } \\
\text { sobre o momento do parto } \\
\text { e promover a reflexão } \\
\text { sobre a violência } \\
\text { obstétrica. }\end{array}$ \\
\hline
\end{tabular}




\begin{tabular}{l|l|l|l|l}
\hline $\begin{array}{l}\text { Agosto/ } \\
2018\end{array}$ & 03 & $\begin{array}{l}\text { Primeiros } \\
\text { cuidados com o } \\
\text { RN }\end{array}$ & $\begin{array}{l}\text { Qual o } \\
\text { conhecimento e } \\
\text { expectativa sobre os } \\
\text { primeiros cuidados } \\
\text { com o recém- } \\
\text { nascido? }\end{array}$ & $\begin{array}{l}\text { Compartilhar os } \\
\text { conhecimentos sobre os } \\
\text { primeiros cuidados com } \\
\text { os recém-nascidos }\end{array}$ \\
\hline $\begin{array}{l}\text { Setembro/ } \\
2018\end{array}$ & 03 & $\begin{array}{l}\text { Expectativas } \\
\text { relacionadas à } \\
\text { amamentação }\end{array}$ & $\begin{array}{l}\text { Qual o sentimento } \\
\text { com relação a } \\
\text { amamentação? }\end{array}$ & $\begin{array}{l}\text { Compartilhar saberes } \\
\text { sobre a amamentação e } \\
\text { sua importância. }\end{array}$ \\
\hline
\end{tabular}

FONTE: COLETA DE DADOS PROBEX

\section{Vivendo e vivenciando as RC}

A primeira temática, cujo tema foi sexualidade na gestação levantou distintas reações entre as participantes, algumas mostrando timidez, referindo não gostar de falar sobre o assunto. Enquanto outras se mostram menos inibidas, trazendo ao grupo suas experiências sexuais. Questões de dúvidas também surgem, por exemplo, ao perguntarem se a penetração poderia afetar o bebê. Em relação à libido, algumas a percebem diminuída primeira fase da gestação. Já outras participantes relataram que sentiam um certo desconforto nos momentos da relação. Por fim, observou-se que aquelas com parceiro fixo relataram ter uma relação sexual mais frequente e confortável sentindo-se seguras para manter o contato com o parceiro.

A segunda temática foi o "momento do parto" com o objetivo de discutir o conhecimento sobre os tipos de parto, e as melhores formas de realizá-lo. Assim, os discentes levaram ideias de técnicas de relaxamento e respiração, e propuseram a construção de um mural com colagens refletindo tal momento.

No andamento das discussões, encontrou-se o espaço para destacar e informar acerca dos serviços do Centro de Parto Normal destinado a oferecer serviços de acompanhamento e assistência ao parto na perspectiva do parto humanizado, situado no Instituto de Saúde Elpídio de Almeida (ISEA). Aquelas que tinham experiência com tal centro, trouxeram à conversa dados sobre o local, como os tipos de partos possíveis e os critérios de admissão exigidos para parir neste espaço. Os relatos mostraram experiências prévias bem sucedidas, e também dúvidas e medos quanto ao uso de alguns equipamentos tais como banheira, bola suíça e massagem, por exemplo.

Para a terceira temática foi trabalhada a violência obstétrica. As participantes foram convidadas a construir um cartaz de maneira coletiva, no qual estava escrito: "Não à Violência!". As gestantes utilizaram materiais para recortar palavras e formar frases relacionadas ao tema, das quais já haviam ouvido por profissionais no momento do parto ou em 
gestações anteriores. Foram evidenciadas frases de conteúdo agressivo como piadas e ofensas do tipo "na hora de fazer o bebê não sofreu assim", realizadas por profissionais de saúde em partos prévios, o que se configura como violência obstétrica.

Notou-se também, um entendimento por parte das gestantes do que seria violência obstétrica e sobre seus direitos no momento do parto, relatando que: "não existe médico ou enfermeiro que manda no procedimento, este é natural, eles estão lá para auxiliar”. Elas ainda demonstraram um conhecimento sobre a episiotomia, sendo esta "um tipo de violência". Ainda foram trazidos relatos de que "o parto normal deve ser visto de forma positiva e não de sacrifício para ninguém".

Apesar de relatos de experiências negativas, houve o desejo de um futuro parto normal, compreendendo que a cesárea é um método a ser utilizado somente em casos de específicos. Ao final da atividade, foi feita uma avaliação pelas gestantes acerca da metodologia de abordagem trazida pela roda de conversa. Todos os relatos evidenciaram teor de positividade no que diz respeito à formação de opiniões e a consolidação do conhecimento sobre uma gestação e partos saudáveis e bem assistidos.

Durante a quarta temática foi abordado o conhecimento dos cuidados com o recémnascido. O grupo preparou uma dinâmica com "mitos e verdades", a fím de trazer o conhecimento e a discussão sobre o tema. A maior parte das participantes já haviam vivenciado anteriormente a experiência de ser mãe, o que tornou a conversa dinâmica e repleta de trocas e vivências enriquecedoras. Com isso, os conhecimentos científicos se entrelaçaram com o conhecimento prévio das gestantes, permitindo que elas se tornassem sobretudo, protagonistas do conhecimento.

$\mathrm{Na}$ quinta roda de conversa foi abordada a temática das expectativas sobre a amamentação. Desse modo, foi discutido sobre a posição correta da criança e da mãe na hora da amamentação, enfatizando a importância e os benefícios do leite materno, da pega correta para evitar ferimento e dor durante a amamentação, e como deve ser o ambiente ideal para a amamentação, além da necessidade de apoio dos familiares. Mais uma vez foi momento de troca de experiência entre as gestantes que já haviam vivenciado este momento, e aquelas que ainda tinham dúvidas ou estavam na primeira gestação.

Algumas usuárias verbalizaram os benefícios da amamentação exclusiva até os seis meses, sendo estes vivenciados tanto pela mulher quanto pela criança. Ainda foram abordadas questões relacionadas à mastite, algo muito comum nas puérperas, sendo esclarecido sobre a 
busca pelo tratamento imediato.

Foi possível evidenciar os resultados desses encontros na vida das participantes por meio de uma reportagem da Revista institucional da UFCG, na qual uma das participante deu o seguinte relato:

\begin{abstract}
Quando começou a fazer o pré-natal na Unidade Básica de Saúde Adalberto César [...] não imaginava que iria aprender tanto sobre o universo da maternidade. E mais: a diarista não tinha ideia de que iria conseguir compartilhar sua experiência de vida e que aquela ação seria libertadora para ela e outras gestantes ali presentes [...] (RODRIGUES, 2019, p. 13).
\end{abstract}

Nesse segundo relato também é perceptível o efeito benéfico das rodas de conversa na vida das participantes:

[...] "Esse assunto foi muito mágico, porque eu consegui me abrir no meio de toda a roda, para um sentimento que estava fechado. Em uma conversa surgiu o abandono, a força, a alegria, como se a gente renascesse das cinzas como uma fênix" (RODRIGUES, 2019, p. 13).

\title{
A relação da equipe e usuários da Unidade Básica de Saúde com os integrantes do Projeto de extensão
}

Com o modelo biomédico, o saber científico se sobrepõe aos demais saberes, impossibilitando uma dialética mais clara entre profissional e usuário. Um dos pontos que acarretam esta problemática é a rotina excessiva na dinâmica do trabalho no setor da saúde, as ações sistemáticas e técnicas que tornam as relações entre usuários e profissionais da unidade básica superficiais, impedindo assim, uma escuta qualificada (SILVA, 2015).

Portanto, na tentativa de implementar a articulação entre usuários do serviço e profissionais de uma forma horizontalizada, contrária à tradicional forma biomédica, é necessário modificar a dinâmica do trabalho, e ampliar a percepção das verdadeiras funções dos autores no processo de prevenção em saúde. Tornando necessária a importância de se conhecer os saberes, crenças, e as opiniões dos usuários, indo para além do viés biológico, partindo das questões sócio-histórico e subjetivas de cada indivíduo.

Deste modo, construir um contato eficaz com os profissionais da unidade básica de saúde, foi de suma importância. Afinal, é esta equipe que norteia e orienta os acadêmicos que visitam a UBS, são eles que disponibilizam quais horários são mais viáveis para a realização das atividades, que informam possíveis alterações no cronograma mensal e ainda explicam como geralmente os usuários do serviço se comportam mediante as ações que visa o cuidado em saúde.

Logo, através das experiências como extensionistas, foi notável o interesse da equipe da 
unidade e demais funcionários nas atividades do projeto, pois mensalmente questionavam como estavam acontecendo as rodas de conversa e observavam como as gestantes estavam lidando e se articulando com cada tema abordado. Além disso, através das conversas entre os profissionais e estudantes, eram explicados os pontos de melhoria e as fragilidade ao decorrer das ações realizadas, potencializando assim a qualidade no compartilhamento dos saberes, entre a equipe, usuárias do serviço e os extensionistas, proporcionando assim uma convivência mais harmônica e produtiva visando o bem estar dos membros da comunidade.

\section{CONCLUSÃO}

A partir das experiências relatadas foi possível promover reflexões sobre a importância da Educação em Saúde utilizando a Roda de Conversa como ferramenta para uma relação usuário/equipe no contexto da atenção primária à saúde. Discentes e usuárias puderam experienciar uma relação horizontal, na qual se colocavam como protagonistas do próprio papel de aprendizagem, se colocando no local de fala e ao mesmo tempo ouvindo o que estava sendo compartilhado.

Portanto, a roda de conversa se mostra como fundamental dentro do processo de Educação em Saúde, possibilitando a troca do conhecimento, permitindo aos usuários práticas de promoção em saúde que possam ultrapassar o individual e se transmitir ao coletivo. A partir do trabalho em grupo, faz-se viável também, o fortalecimento da comunidade vigente àquela unidade, quando juntos compartilham o conhecimento, conhecem uns aos outros, os problemas e estratégias para se vencer as barreiras pessoais e comunitárias.

Diante da relevância que este projeto teve para as gestantes e para os profissionais da UBS em questão, torna-se imprescindível a realização de outras trabalhos acerca dessa temática e que possam trazer suas experiências, visto que o conhecimento prévio que as gestantes relataram, contribuiu no processo de construção dos saberes. Além disso, as experiências vivenciadas pelos extensionistas nas atividades como um todo, proporcionaram momentos de aprendizado muito além daquele oferecido em sala de aula.

Além disso, continuar as pesquisas na mesma comunidade pode servir como parâmetro para verificar o progresso e transformação dos envolvidos, considerando que as usuárias participantes, continuam utilizando a UBSF para outros serviços e compartilham os novos saberes construídos. Logo, é relevante avaliar se houve mudanças permanentes e quais impactos a longo prazo foram possíveis através dos discursos da equipe e dos usuários. 


\section{REFERÊNCIA}

BARBOSA, M.C.S.; HORN, M.G.S. Projetos pedagógicos na Educação Infantil. Porto Alegre: Artmed, 2008.

BASTOS, A. B. B. I. A técnica de grupos-operativos à luz de Pichon-Rivière e Henri Wallon. Psicólogo Informação, v. 14, n. 14, p. 160-160, jan./dez. 2010.

BRASIL. Ministério da Saúde. Portaria no. 2.436 de 21 de setembro de 2017. Brasília: Diário Oficial [da] República Federativa do Brasil, 2017.

CARRARO, T.E. et al. Socialização como processo dinâmico de aprendizagem na enfermagem. Uma proposta na metodologia ativa. Investigación y Educación en Enfermería, v. 29, n. 2, p.248-254, 2011.

DARIUS,R.P.P. et al. O uso da metodologia da problematização para o desenvolvimento de projeto integrador no curso de pedagogia. Revista Ibero-Americana de Estudos em Educação, [S.1.], p. 983-1004, mar. 2017. ISSN 1982-5587. Disponível em: https://periodicos.fclar.unesp.br/iberoamericana/article/view/9809/6578. Acesso em: 06 may 2019.

FERNANDES, M.C.P. and BACKES, V.M.S.Educação em saúde: perspectivas de uma equipe da Estratégia Saúde da Família sob a óptica de Paulo Freire. Rev. bras. enferm. [online]. 2010, vol.63, n.4, pp.567-573. ISSN 0034-7167. https://doi.org/10.1590/S003471672010000400011.

FREIRE, P. Educação como prática da liberdade. 1. ${ }^{a}$ ed. 1967. 28. ed. Rio de Janeiro: Paz e Terra, 2005.

LOPES, M. Sobre Estudos De Casos E Relatos De Experiências .... Revista da Rede de Enfermagem do Nordeste [en linea] 2012, 13 [Fecha de consulta: 22 de agosto de 2019] Disponible en:http://www.redalyc.org/articulo.oa?id=324027983001 ISSN 1517-3852

RODRIGUES, S. Ensinando e aprendendo. UFCG Revista - Assessoria de Comunicação da UFCG (ASCOM). n $^{\circ} 08$ março de 2019 UFCG Revista No 08 by UFCG - issuu.

SAMPAIO, J.,et al. Limits and potentialities of the circles of conversation: analysis of an experience with young people in the backcountry of Pernambuco, Brazil. Interface

(Botucatu). 2014; 18 Supl 2:1299-1312.

SILVA, S.F.; NETO, J.F.M. Saber Popular E Saber Científico. Revista Temas em Educação, João Pessoa, v.24, n. 2, p. 137-154, jul.-dez. 2015 